\title{
Resource Curse: Experience Study on Economic Development of Petroleum Countries
}

\author{
Yuan Yuan ${ }^{1, *}$ \\ ${ }^{1}$ Lanzhou University of Technology, Gansu, China
}

\begin{abstract}
This paper studies the causes of "resource curse" from the perspective of "national utilization of petroleum resources" and uses the samples of eight typical oil resource-rich countries to study their national economic growth status. Empirical studies show that the resource curse effect of most countries is caused by "Dutch disease". Relying too much on the development of the oil resources industry, with the unreasonable industrial structure, the excessive export of oil resources, and the "extrusion effect" of production factors are the reasons that delay the technological innovation and development of the industry and inhibit the balanced development of other industries.
\end{abstract}

\section{Introduction}

Resource Curse, also known as Paradox of plenty, means that a country has large amounts of non-renewable natural resources, which instead slow the process of industrialization and make industrial transformation more difficult, falling into the situation of the single economic structure of over-reliance on the relevant energy industry. Contrary to conventional cognition, empirical evidence shows that most natural resource-rich countries grow slower than those with relatively scarce natural resources.

This paper studies the causes of the "resource curse" from the perspective of "national utilization of petroleum resources". The data uses samples of eight typical oil resource-rich countries to study their economic growth in Iran, Libya, Venezuela, Iraq, Kuwait, Mexico, Nigeria and Norway. These countries are at the world's leading level, are rich in oil resources, and can completely rely on oil resources to develop their own countries. Except that Norway is developed, the rest are developing countries. It is worth mentioning that Norway is also recognized by the world that has got rid of the "resource curse", and the

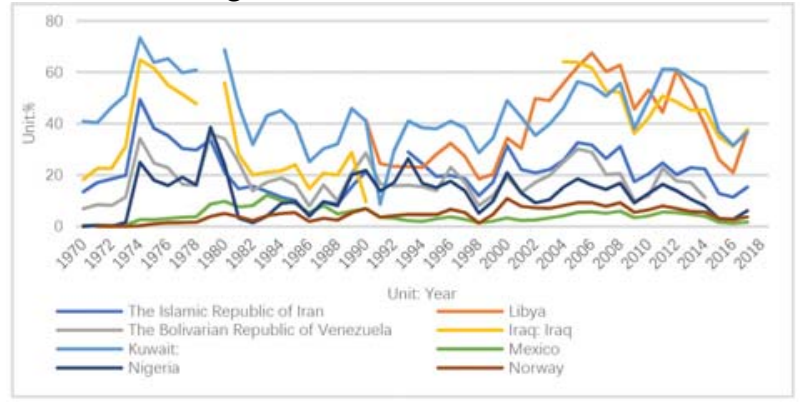

Fig. 1. Eight Oil Rent (percentage of GDP) richness of natural resources is positively related to economic development.

From the Figure 1, the proportion of oil rent in eight countries is scattered, with Kuwait floating at 50\% from 50 to 2018 , occupying half of GDP and even $72 \%$ in 1974 , mainly from oil resources. Mexico and Norway have a relatively lowest share of oil resources, with historical data hovering below $10 \%$. And that of the remaining five countries all float in the $10 \%$ to $30 \%$ range. Through the Figure 2, it is noted that the trend chart of total natural resources rent in the eight countries is basically the same as the Figure 1. This shows that the industry about natural resources in these eight countries is mainly derived from oil, and that oil resources have almost become the only source of foreign exchange for the energy industry. According to the time trend chart of the per capita GDP growth rate of the eight countries (see Figure 3), Iraq and Libya are partially outlier, with too high and too low per capita growth rates, possibly related to the war between the two countries. Other countries' per capita GDP growth rate fluctuated around 0 , with a mean of approximately 0 . On average, Kuwait and Iran have more negative years.

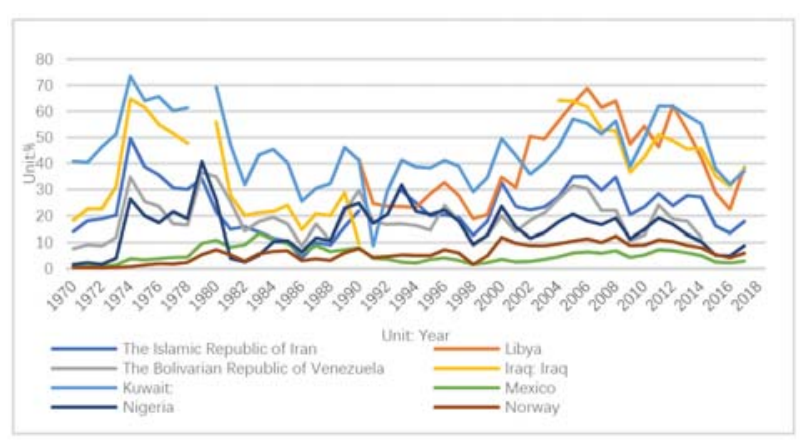

Fig. 2. Total Eight-Country Natural Resource Rent (a percentage of GDP)

\footnotetext{
*Corresponding author: $\underline{812099766 @ \text { qqq.com }}$
} 


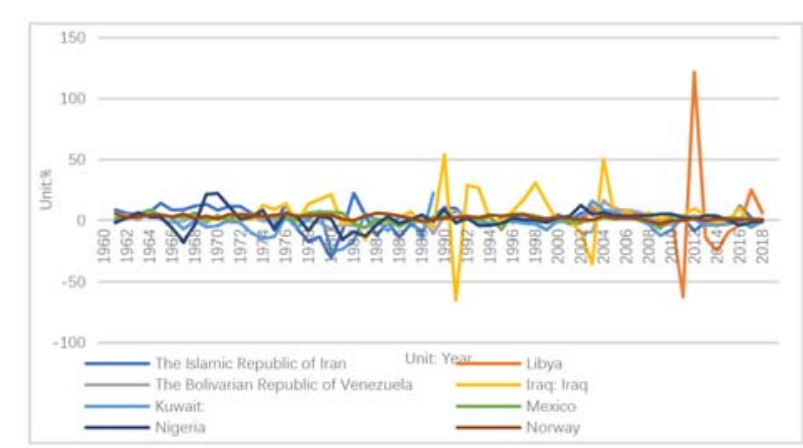

Fig. 3. GDP per capit

\section{Theoretical foundation and transmission mechanism}

According to the existing literature, the economic development of the country is related to the factor use of domestic resources, which can be roughly divided into the following two categories. Domestic rich natural resources accumulated original capital for the takeoff of its national economy. Coal mines and iron ore are rich, which manifest themselves in "Resource Blessing", such as Great Britain, Germany, the United States, Canada, and Australia; Regions and natural resource-rich countries plunge them into a depressed economic environment. In a period of time, per capita GDP even showed negative growth. Iran, Libya, Venezuela, Iraq, Kuwait, Mexico, Nigeria and other countries have shown a "resource curse" situation. These countries are particularly rich in petroleum resources and are also the focus of this paper.

The abundance of resources indirectly leads to the lagging economic development of the country, and the transmission mechanism is summarized as follows. Firstly, resource path dependence, the national interest groups rely heavily on the exploitation of relevant resources, thus ignoring the accumulation of human resources and technological innovation, ultimately inhibiting economic growth[1][2]. Secondly, the government's rent-seeking corruption. As the profit margin of resource-rich industries is higher than other industries, many enterprises have bribed the government in order to enter the market. At the same time, it also leads to a large influx of human and capital resources into domestic resource-utilization industries, resulting in lagging contraction of other industries and unbalanced economic development[3]. Thirdly, the "Dutch disease" phenomenon, sufficient resources led to rising prices, deteriorating trade conditions, and inhibiting exports [4].

\section{Empical analysis}

\subsection{Model construction and index description}

This paper selects eight rich oil countries, Iran, Libya, Venezuela, Iraq, Kuwait, Mexico, Nigeria and Norway, and uses the relevant data provided by the World Bank to verify whether local national resources, especially excessive reliance on oil resources, will lead to the stagnation of economic development.
According to the above theory and related conduction mechanism, this paper constructs a simple measurement model to verify the relationship between the utilization rate of oil resources and the GDP growth rate per capita. For possible fixed effects, virtual variables of countries are added. And time trend items are added for possible time effects.

$$
\text { gdpper }_{\text {it }}=\beta_{0}+\beta_{1} \text { ratio }_{\text {it }}+\beta_{2} \mathrm{D} \cdot \text { country }+\beta_{3} \mathrm{t}+\mu_{\mathrm{i}}+\varepsilon_{\mathrm{it}}
$$

This paper builds long panel data about eight countries from 1970 to 2017.gdpper represents annual per capita GDP growth rates in relevant countries, while ratio represents oil rents represent the proportion of natural resource rents. D-country represents virtual variables representing eight countries, $\mathrm{t}$ is time trend term, $u_{i}$ is intercept term for individual heterogeneity, and $\varepsilon_{i t}$ is perturbation term varying over time.

\subsection{Relevant test of the model}

Due to the data used in this model, the time dimension $\mathrm{T}$ is large, the individual has more information volume, while the $\mathrm{N}$ is small, so it is the long panel data. It is necessary to detect the group isovariance, group correlation and group autocorrelation of the data, and finally select the appropriate measurement method.

According to the Wald test, under the original assumption of "equal disturbance term variance for different individuals", its statistics 14995.45 is far greater than the critical value and strongly reject the isovariance, so it can be assumed that there is intergroup heterovariance in the long panel data in this paper.

According to the Breusch-Pagan LM test for the intergroup correlation, under the original hypothesis that "there is no inter-group correlation", if established, the correlation coefficients of the different individual perturbation terms calculated by residual are close to 0 . According to the "residual correlation coefficient matrix", the LM statistics of 111.63 is greater than the critical value, so the original assumption of "no simultaneous correlation" is strongly rejected, and a same-period correlation exists.

With the Wald test of in-group autocorrelation, under the original assumption of "no intra-group autocorrelation", the statistic of 0.88 is less than the critical value and the $p$ value is 0.3794 , and the original assumption of "no intra-group autocorrelation" is not rejected.

Table 1. Inspection of the heterovariance between the groups

Modified Wald test for groupwise heteroskedasticity in fixed effect regression model

\begin{tabular}{|c|c|}
\hline H0: sigma(i) & $=\operatorname{sigma}^{\wedge}$ \\
\hline $\operatorname{chi} 2(8)=$ & 14995.45 \\
\hline Prob $>$ chi $2=$ & 0.0000 \\
\hline
\end{tabular}


Table 2. Related tests between groups

\begin{tabular}{|c|}
\hline Correlation matrix of residuals: \\
\hline 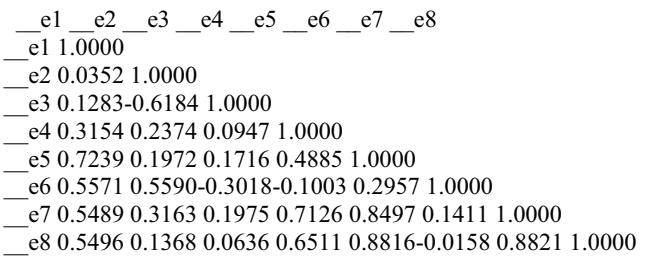 \\
\hline $\begin{array}{l}\text { Breusch-Pagan LM test of independence: } \operatorname{chi} 2(28)=111.630, \operatorname{Pr}= \\
0.0000 \\
\text { Based on } 11 \text { complete observations over panel units }\end{array}$ \\
\hline
\end{tabular}

Table 3. Self-related inspection in the group

\begin{tabular}{l}
\hline Wooldridge test for autocorrelation in panel data \\
\hline H0: no first-order autocorrelation \\
$\mathrm{F}(1,7)=0.880$ \\
Prob $>\mathrm{F}=0.3794$ \\
\hline
\end{tabular}

\subsection{Regression Results}

According to the above test of the data, the disturbance term has inter-group isovariance and inter-group correlations, and the virtual variable least squares (LSDV).
At this time, just use the steady standard "heterovariance between group, inter-group correlation" error, namely "panel correction standard error" (PCSE).

According to the regression results, the time trend term $t$ is not significant, and there is no time trend. In addition to Libya, the percentage of oil rent for total natural resource rent in seven countries was significantly negative to GDP at 5\% (based on Iraq), and the average ratio coefficient of Iraq, Iran, Mexico, Venezuela, Nigeria and Norway fluctuated at about-5, indicating that the percentage of total natural resource rent increased and the national GDP growth rate decreased by $5 \%$. Notably, the absolute value of the ratio coefficient in Kuwait is significantly greater than the average of the seven other countries, at -8.717 , and is significantly not 0 at the $1 \%$ level.

Among the selected sample countries, the economic development of Iraq, Iran, Mexico, Venezuela, Nigeria, Norway and Kuwait is significantly affected by the single development of the resource industry. The growth rate of per capita GDP is negatively related to the single use of resources, and the resource curse effect of Kuwait is particularly serious. As for Libya's return coefficient is not significant, the possible reason is the domestic war, which is far greater than the effect of the resource curse.

Table 4. Regression results: Panel-corrected

\begin{tabular}{|c|c|c|c|c|c|c|c|}
\hline gdpper & Coef. & St.Err. & $\mathrm{Z}$ & $\mathrm{p}>|\mathrm{z}|$ & {$[95 \%$ Conf } & Interval] & Sig \\
\hline ratio & -4.456 & 1.508 & -2.95 & 0.003 & -7.421 & -1.500 & $* * *$ \\
\hline $\mathrm{t}$ & 0.029 & 0.045 & 0.64 & 0.521 & -0.060 & 0.117 & \\
\hline \multicolumn{8}{|l|}{ Country } \\
\hline Iran & -5.700 & 2.459 & -2.32 & 0.020 & -10.521 & -0.880 & ** \\
\hline Libya & -2.715 & 10.062 & -0.27 & 0.787 & -22.437 & 17.007 & \\
\hline Mexico & -5.214 & 2.380 & -2.19 & 0.028 & -9.879 & -0.549 & $* *$ \\
\hline Venezuela & -5.804 & 2.029 & -2.86 & 0.004 & -9.781 & -1.826 & $* *$ \\
\hline Nigeria & -5.519 & 2.363 & -2.34 & 0.019 & -10.149 & -0.888 & ** \\
\hline Norway & -4.744 & 2.397 & -1.98 & 0.048 & -9.442 & -0.046 & $* *$ \\
\hline Kuwait & -8.717 & 2.100 & -4.15 & 0.000 & -12.834 & -4.601 & $* * *$ \\
\hline Constant & 9.530 & 2.865 & 3.33 & 0.001 & 3.914 & 15.146 & $* * *$ \\
\hline \multicolumn{2}{|c|}{ Mean dependent var } & \multicolumn{2}{|c|}{1.243} & \multicolumn{2}{|c|}{ SD dependent var } & \multicolumn{2}{|c|}{10.911} \\
\hline \multicolumn{2}{|c|}{ Overall r-squared } & \multicolumn{2}{|c|}{0.046} & \multicolumn{2}{|c|}{ Number of obs } & \multicolumn{2}{|c|}{327.000} \\
\hline \multicolumn{2}{|c|}{ Chi-square } & \multicolumn{2}{|c|}{79.38} & \multicolumn{2}{|c|}{ Prob $>$ chi 2} & \multicolumn{2}{|c|}{0.0000} \\
\hline \multicolumn{2}{|c|}{ R-squared within } & \multicolumn{2}{|c|}{0.004} & \multicolumn{2}{|c|}{$\mathrm{R}$-squared between } & \multicolumn{2}{|c|}{1.0000} \\
\hline
\end{tabular}

\section{Conclusion}

The panel measurement result reflects that the resource curse effect of most countries is caused by "Dutch disease". The interpretation variable in the model is the proportion of oil rent in the total natural resource, and this index is inversely proportional to the per capita GDP growth rate, drawing the following conclusion.

The industrial structure of the oil country is unreasonable and over-relies on the development of the oil resource industry. The natural resources are abundant, but the country has not adopted diversified industries, leading to the contraction of other industries or departments. Even if the overall output of the country is very high, the per capita welfare does not increase, and the growth of per capita GDP has been suppressed.

The excessive export of oil resources, leading to the appreciation of the domestic currency, affecting capital and human resources into the manufacturing and agricultural industries, can only survive by the government's import protection policies and subsidies, inhibiting the development of other sectors.

The development of energy industry leads to the higher remuneration rate of the industry higher than that of other industries, which will lead to the transfer of national factor resources to the energy industry, leading to the "extrusion effect" of production factors, delaying the technological innovation and development of the industry and inhibiting the balanced development of other industries.

\section{References}

1. Xu Kangning, Shao Jun. Natural resources abundance and economic growth: a reexamination of the 
'Resource Curse' hypothesis[J]. The journal of world economy, 2006(11) : $38-47$.

2. Wang Rong, Zhu Cuiping. Reflections of institutional quality related between resources and growth[J]. Journal of Tsinghua University (philosophy and social sciences), 2008(1):152-158.

3. Ding Juhong, Deng Kebin. Government intervene, natural resource and economy development: based on regional panel data study of China[J]. China industrial economics, 2007(7) : 56-64.

4. Zheng Yi, Qin Bingtao. Political institutions, resource endowment and economic growth[J]. World economy study, 2016(4) : $66-77$. 